\title{
Dispersal response to climate change: scaling down to intraspecific variation
}

\author{
Elvire Bestion $^{1,2, *}$, Jean Clobert ${ }^{1}$, Julien Cote $^{2, *}$
}

Ecology Letters 2015, 18 (11), 1226-1233, doi : 10.1111/ele.12502

\author{
${ }^{1}$ CNRS USR 2936, Station d'Ecologie Expérimentale de Moulis, F-09200 Moulis, France \\ 2 CNRS, Université Toulouse III Paul Sabatier, ENFA; UMR5174 EDB (Laboratoire \\ Évolution \& Diversité Biologique); 118 route de Narbonne, F-31062 Toulouse, France. \\ e.bestion@exeter.ac.uk; julien.cote@univ-tlse3.fr
}

\begin{abstract}
Range shift, a widespread response to climate change, will depend on species abilities to withstand warmer climates. However, these abilities may vary within species and such intraspecific variation can strongly impact species responses to climate change. Facing warmer climates, individuals should disperse according to their thermal optimum with consequences for species range shifts. Here we studied individual dispersal of a reptile in response to climate warming and preferred temperature using a semi-natural warming experiment. Individuals with low preferred temperatures dispersed more from warmer seminatural habitats while individuals with higher preferred temperatures dispersed more from cooler habitats. These dispersal decisions partly matched phenotype-dependent survival rates in the different thermal habitats, suggesting adaptive dispersal. This process should result into a spatial segregation of thermal phenotypes along species moving ranges which should facilitate local adaptation to warming climates. We therefore call for range-shift models including intraspecific variation in thermal phenotype and dispersal decision.
\end{abstract}

Keywords: dispersal syndrome; climate change; preferred temperature; Zootoca vivipara; thermal biology; inter-individual variation; condition-dependent dispersal; non-random dispersal 


\section{Introduction}

Recent climate change has profoundly impacted species habitat. At the southern margin of species distributions, environmental conditions that were once suitable for a many animal and vegetal species have shifted to hotter, unsuitable conditions, while at the northern margin, conditions that were once too cold for species to invade have become suitable. Facing warming climate, species can adapt to their new thermal conditions (through phenological/physiological changes, Parmesan 2006) or they can shift their range to track their climatic niche (Parmesan 2006; Thomas 2010). Indeed, a recent study showed that $68 \%$ of all species have expanded their range polewards due to climate change (Thomas 2010), while numerous range retractions at the southern margins have also been witnessed (Thomas et al. 2006).

Conceptual frameworks predict that species less adapted to the new thermal conditions will be the ones that will suffer larger range retractions (Comte et al. 2014). However, these frameworks consider species as uniform ensembles, neglecting the variability that can occur between populations and between individuals within populations. Within species and populations, individuals considerably vary both genetically (Pauls et al. 2013) and phenotypically (Bolnick et al. 2011). Such variations are crucial for population, community and ecosystem functioning (Hughes et al. 2008; Bolnick et al. 2011) and can strongly shape species responses to current environmental changes (Sih et al. 2012; Valladares et al. 2014; Moran et al. 2015). For instance, in ectotherms, thermal niche strongly varies among individuals of a species, with some individuals preferring higher temperatures than others (Gvoždík \& Castilla 2001; Carretero et al. 2005; Artacho et al. 2013) and this variation can be as strong as interspecifc variation. In sub-Antartic weevils, species level explained four times 
less variance in critical thermal minimum (CTmin) than intraspecific variation in response to local conditions, while inter- and intra-specific variation in critical thermal maximum (CTmax) were similar (Klok \& Chown 2003). In lizards, the intraspecific variance in Liolaemus lizards CTmin was close to the variance observed for 135 reptile species, while variation in CTmax was much lower at the intraspecific level (Araújo et al. 2013). Furthermore, intraspecific variation is often strong within populations and maintained in the entire species range (e.g. Gvoždík \& Castilla 2001; Carretero et al. 2005). While we could expect thermal phenotype to be assorted along species range and thus differ only among populations, such intrapopulation variation is maintained due to local spatial and temporal variability in climatic conditions and/or of alternative life-history strategies related to thermal phenotypes and with equal fitness (Lepetz et al. 2009). In the context of global warming, this variation should create within-species and within-population differences in the adaptation to local thermal conditions leading to the counterselection or the departure of phenotypes less adapted to warmer conditions. Indeed, individual dispersal propensity results from an interaction between individual phenotype and local conditions, with individuals that are locally less adapted dispersing (Clobert et al. 2009). By neglecting intraspecific variation in thermal niche, not only do we prevent the understanding of climate impacts on this important dimension of biodiversity (Pauls et al. 2013), but we could also miss an important mechanism for species range shift in a changing climate (Dytham et al. 2014). Indeed, a recent modeling work showed that neglecting interpopulation variation in thermal physiology could lead to overly optimistic predictions of range shifts with climate change when dispersal possibilities were restricted (Valladares et al. 2014). However, despite interesting modeling studies on interpopulation variation (Cobben et al. 2012; Valladares et al. 2014), the effect of intrapopulation variation of thermal niche on species and population responses and range shifts to climate change have not been empirically and even more experimentally studied. 
Here we experimentally investigated how individual differences in thermal physiology at birth can explain variation in natal dispersal from different climatic conditions in common lizards (Zootoca vivipara). Common lizards are good study models because as most ectotherms, they are particularly vulnerable to climate change (Sinervo et al. 2010; Huey et al. 2012). Indeed, $30 \%$ of common lizard populations surveyed in 46 sites at the southern margin of their distribution have already gone extinct (Sinervo et al. 2010). Common lizards also display an intraspecific variation in thermal optimum (Artacho et al. 2013) and have been shown to respond differently to changing climates depending on phenotypic traits linked to thermal physiology (Lepetz et al. 2009). Interestingly, although there is low variation in preferred temperatures among populations, preferred temperatures considerably vary within populations and this variation is maintained along latitudinal and altitudinal gradients (Gvoždík \& Castilla 2001; Carretero et al. 2005). Moreover, dispersal tendency itself has been shown to depend on climatic conditions in this species, with dispersal propensities varying with pre- and postnatal temperatures (Massot et al. 2008).

We studied common lizard dispersal propensity depending on experimentally manipulated climatic conditions and individual thermal phenotype into semi-natural enclosures connected together through corridors allowing dispersal (Legrand et al. 2012). We measured preferred temperature (a proxy of thermal optimum, Huey et al. 2012) in neonatal lizards in a laboratory gradient and released them into semi-natural enclosures along with adults and yearlings to create ten lizard populations. Populations were submitted to a 'present climate' (existing local area climate) or a 'warm climate' treatment $\left(\sim 2-3^{\circ} \mathrm{C}\right.$ warmer than ambient temperatures), coherent with IPCC climate change projections for southern Europe by 2080 (IPCC 2013). Enclosures were connected to corridors allowing monitoring juvenile dispersal throughout the summer. We demonstrated that natal dispersal propensity depended on the interaction between natal preferred temperature and climatic conditions in natal habitats. We further 
showed that climate-dependent dispersal decisions translated into survival differences and could therefore reflect adaptive dispersal decisions.

\section{Material and Methods}

Species and experimental system Common lizards are small live bearing lacertid lizards inhabiting dense vegetation habitats. They are widely distributed, ranging from Scandinavia to northern Spain (Agasyan et al. 2010). Lizards hibernate from October to March. After 2 months of gestation, females lay $\sim 5$ soft-shelled eggs. Juveniles emerge shortly after and are immediately independent (Massot et al. 1992). Dispersal occurs primarily in their first few months of life (Cote \& Clobert 2007). Preferred temperature varies relatively little among populations (e.g. mean $\pm \mathrm{SD}, \mathrm{T}_{\mathrm{p}}=32.1 \pm 2.9^{\circ} \mathrm{C}$ in Austria, $32.3 \pm 2.5^{\circ} \mathrm{C}$ in Belgium, $31.4 \pm$ $1.3{ }^{\circ} \mathrm{C}$ in Czech Republic, $31 \pm 0.9{ }^{\circ} \mathrm{C}$ in Great Britain, Patterson \& Davies 1978; Van Damme et al. 1990; Gvoždík \& Castilla 2001; reviewed in Carretero et al. 2005), while it varies considerably within populations, even when controlling for differences in sexes and age classes $\left(\sim 5-6^{\circ} \mathrm{C}\right.$, Carretero et al. 2005). This variation is maintained along large latitudinal and altitudinal gradients (Belgium to Spain, Carretero et al. 2005, 250 m to 1450 m, Gvoždík 2002).

We used lizards captured in 2010 from natural populations of the Cévennes mountains (France, $44^{\circ} 27^{\prime} \mathrm{N}, 3^{\circ} 44^{\prime} \mathrm{E}$ ), close to the southern margin of the distribution. Lizards were marked by toe-clipping and translocated to the Metatron, a system of semi-natural caged enclosures (Station of Experimental Ecology in Moulis, France, $43^{\circ} 01^{\prime} \mathrm{N}, 1^{\circ} 05^{\prime} \mathrm{E}$, Legrand $e t$ al. 2012) offering 48 interconnected enclosures (10 x $10 \mathrm{~m})$ containing natural lizard habitat (dense vegetation, logs, rocks). Enclosures are delimited by tarpaulins buried $30 \mathrm{~cm}$ into the ground, preventing escape and terrestrial predation, and enclosed with nets preventing avian predation and allowing enclosures' isolation. Enclosure size is equivalent to lizards' core 
home range size (Boudjemadi et al. 1999). Temperature, illuminance and hygrometry within enclosures are monitored continuously and can be manipulated through motor-driven shutters, allowing creating different climatic conditions inside enclosures.

Enclosures can be connected to each other through two one-way 19 meter-long S-shaped corridors. This distance corresponds to the minimum dispersal distance observed in natural common lizard populations (Clobert et al. 1994). Indeed, in nature, individuals moving $30 \mathrm{~m}$ or more from their natal site (distance between the center of two connected enclosures) have been defined as dispersers because they rarely return to their natal site ( $2 \%$ of all individuals, Clobert et al. 1994), and dispersal patterns (rate, timing and causes) observed in the field and in such enclosed systems are similar (Boudjemadi et al. 1999; Cote \& Clobert 2007; Bestion et al. 2014). A pitfall trap at the end of each one-way corridor allows capturing dispersers. Conditions within corridors do not allow lizards to settle permanently (poor vegetation, i.e. hostile habitat for lizards), thus excluding the possibility that lizards cross the corridor as part of their everyday movements. However, individuals entering the corridors for exploration purposes are able to turn back to their original enclosures before the pitfall trap (Boudjemadi et al. 1999). Lizards caught in the trap while leaving their enclosure can be considered as dispersers as the return rate is very low and similar to those in natural populations (Boudjemadi et al. 1999; Cote \& Clobert 2007).

In May 2013, repeated capture sessions allowed capturing all surviving lizards (adults: 161 females, 113 males; yearlings: 74). Lizards were kept in the laboratory in individual terraria according to methods described in Bestion et al. (2014). One week after capture, we measured preferred temperatures on adults and yearlings to ensure preferred temperatures were variable. Preferred temperature was similar to preferences found in most lizard populations (reviewed in Carretero et al. 2005, Table A1 in Appendix) and was widely variable among individuals (mean $\pm \mathrm{SD}, 32.5 \pm 5.8, \mathrm{n}=346$ ). Females gave birth to 387 viable offspring from June $15^{\text {th }}$ 
to July $31^{\text {th }}$. Offspring were marked and measured for snout-vent length (to the nearest $\mathrm{mm}$ ) and mass (nearest $0.001 \mathrm{~g}$ ) at discovery; and were sexed by counting ventral scales. Three days after birth, we tested offspring for preferred temperature in a laboratory thermal gradient. Families were then released into the enclosures.

Preferred temperature test Tests were performed in eight $80 \times 20 \times 40 \mathrm{~cm}$ glass terraria in a controlled temperature room $\left(18^{\circ} \mathrm{C}\right)$. Marks on the floor divided each terrarium in eight $10 \mathrm{~cm}$ zones, and a movable separation created a $10 \mathrm{~cm}$ acclimatization zone at the end of the terrarium. A light bulb $(60 \mathrm{~W})$ at the opposite end of the terrarium created a temperature gradient from $45.8 \pm 0.8{ }^{\circ} \mathrm{C}$ to $19.4 \pm 0.6{ }^{\circ} \mathrm{C}$. We obtained a continuous quantification of this gradient with thermometers placed every $10 \mathrm{~cm}$ in an additional terrarium. To ensure minimal disturbance, a curtain isolated the testing part of the room. All individuals were maintained without heat and light source on the morning of the test in the controlled temperature room and were tested within few hours. This ensured that there was no difference in heat needs amongst individuals and prevented differences due to the hour of the day. Each morning, one juvenile was placed into each testing terrarium in the acclimatization zone, at the coolest part of the gradient, and left for 10 minutes to acclimatize before removing the separation. Video cameras above terraria recorded juveniles' position during 30 minutes. Video data was analyzed using The Observer software. We calculated preferred temperature as the mean of the temperatures of the zones where the lizard stayed during the experiment weighted by the time spent at each position. This preferred temperature, a good proxy of individual thermal optimum (Huey et al. 2012), varied at birth $\left(32.3 \pm 6.1{ }^{\circ} \mathrm{C}\right)$ and was not related to other behavioral traits ( $p>0.13$ activity, exploration, sociability measured for another study). Moreover, we tested the repeatability of preferred temperature over two weeks on another set of juveniles. 
Release and dispersal monitoring Ten enclosures were chosen to maintain ten lizard populations. We attributed one of the two climate treatments to enclosures in order to have homogenous vegetal cover and composition between treatments. Climate treatments were applied between June and October; a 'present climate' (PC) level in which automatic shutters above the enclosures were allowed to close when temperature exceeded $28^{\circ} \mathrm{C}$ and a 'warm climate' (WC) level in which shutters closed only when temperature exceeded $38^{\circ} \mathrm{C}$. Enclosed habitats are warmer than outside habitats. Closing the shutters stopped temperature from rising, evening out temperature peaks. As a result, 'present climate' enclosures showed similar summer temperatures to outside while 'warm climate' enclosures were on average 2 and $3{ }^{\circ} \mathrm{C}$ warmer for respectively summer mean and maximum daily temperature (mean daily temperatures between mid-June and mid-September, PC: $26.3 \pm 0.3{ }^{\circ} \mathrm{C}$, WC: $28.3 \pm 0.2{ }^{\circ} \mathrm{C}$, mean $\pm \mathrm{SE}, \mathrm{F}_{1,147}=13, \mathrm{p}<0.001$; maximum daily temperatures: PC: $29.1 \pm 0.3{ }^{\circ} \mathrm{C}, \mathrm{WC}: 32.4$ $\left.\pm 0.4{ }^{\circ} \mathrm{C}, \mathrm{F}_{1,147}=35, \mathrm{p}<0.001\right)$, coherent with climate change projections for southern Europe $\left(3^{\circ} \mathrm{C}\right.$ temperature increase by 2080, IPCC 2013).

On June $26^{\text {th }}$, 113 males and 74 yearlings were released into the Metatron to form 10 populations homogeneous for their density. 154 Females and 348 juveniles were released $6 \pm$ 3 days after laying. Juveniles were released in a split-clutch design, half of the clutch in one treatment and half in the other, all without their mothers who were released in a different enclosure. This design allowed controlling for a family effect as siblings are not independent in terms of dispersal. Each population included $7 \pm 1$ adult males, $12 \pm 1$ adult females, $7 \pm 2$ yearlings, and $35 \pm 3$ juveniles, conforming with local densities in natural populations (Massot et al. 1992; Bestion et al. 2015). There were no differences between treatments in juvenile birth-date, snout-vent length, mass and preferred temperature at release $(p>0.7$ for all). 
Corridors were maintained closed until we released all juveniles to homogenize time allowed to disperse among juveniles and acclimate lizards. Few days after releasing the last family, we opened the corridors from each enclosure to allow dispersal. Pitfall traps were checked daily for dispersers until September $19^{\text {th }}$. Dispersers were identified and released thereafter in another enclosure in a crossed design: half of the dispersers from each climatic treatment were released in present climate, and half in warm climate. The number of dispersers released into each enclosure was low $(3 \pm 1)$ and did not strongly change population density. This crossed design allowed testing whether dispersal increased lizard fitness by finding more suitable environmental conditions. From September $20^{\text {th }}$ to October $13^{\text {th }}$ three capture-recapture sessions allowed to assess summer survival, allowing to capture $93 \%$ of survivors (Bestion et al. 2014).

Statistical analysis We first tested the repeatability of preferred temperature with rpt.adj function in rptR package with R v2.15.2 (Nakagawa \& Schielzeth 2010) and calculated a broad sense heritability of preferred temperatures as twice the percentage of variation among families in models including only family random intercept (Falconer \& Mackay 1996).

Then we modeled the impact of climatic conditions and preferred temperature on juvenile dispersal probability. Dispersal was tested on the 206 individuals that survived through the summer to avoid confounding residency and mortality. Out of them, 4 individuals could not be tested for preferred temperature at birth and were excluded from the analysis. The 5 individuals which dispersed more than once were only considered for the first dispersal event.

We performed generalized mixed models with a binomial distribution and a logit link using glmer procedure in $\mathrm{R}$ v3.1.1 ( $\mathrm{R}$ core team, 2013). Fixed effects included juvenile natal preferred temperature, temperature treatment in the Metatron and the interaction between 
preferred temperature and temperature treatment. We also included birth-date as a continuous covariate as it could potentially affect dispersal. We added the identity of juvenile family and of the Metatron enclosure nested within the temperature treatment as random intercepts to account for variation due to potential differences among families and enclosures. We first fitted three full models with family random intercept, enclosure random intercept and family and enclosure random intercepts and compared them through their AIC to select for the best random component structure (Zuur et al. 2009). The best model included enclosure random intercept only. We compared all combinations of fixed effects through their AIC, and performed Wald chi-square type II tests on the best model to evaluate the impact of each variable. In the figure representing the interaction, we arbitrarily divided data per quartile of the preferred temperature distribution for clarity purposes (Fig. 1).

Finally, we investigated summer survival depending on the climatic treatments before and after dispersal with generalized linear models, using a binomial distribution and logit link. For this analysis, we considered the survival of all dispersers (46 individuals). The low sample size did not allow including enclosure identity.

\section{Results}

Natal preferred temperature varied at birth (mean \pm SD: $32.9 \pm 6.1^{\circ} \mathrm{C}$ ), was repeatable over two weeks $(\mathrm{R}=0.432[0.193,0.54]$ estimate $[\mathrm{CI}], \mathrm{p}=0.009)$ and had a broad-sense heritability of 0.37 . Overall, $19 \%$ of juveniles that were released dispersed. The best model for dispersal propensity contained climatic conditions, individual natal preferred temperature, their interaction and date of birth (Table A2 in Appendix). In 'present climate', dispersal propensity was positively related to natal preferred temperature whereas this relationship was negative in 'warm climate' (interaction climate $x$ preferred temperature: estimate \pm SE: -0.21 $\pm 0.08, \chi^{2}=6.74, \mathrm{p}=0.009$, Fig. 1). 


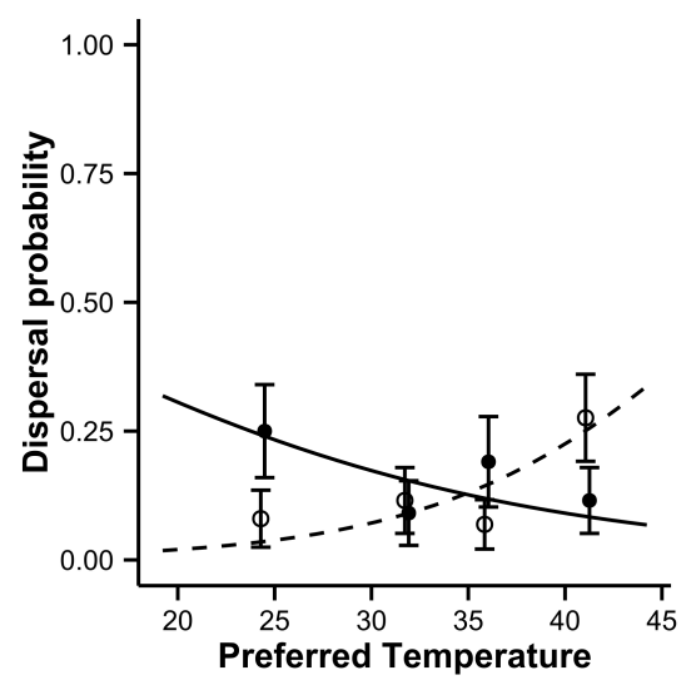

Figure 1: Juveniles dispersal probability depending on natal preferred temperature and on the temperature treatment within the enclosures. White dots, dashed lines: present climate treatment. Black dots, solid lines: warm climate treatment. Dots and error bars represent dispersal probability averaged by quartile of the preferred temperature distribution (mean \pm SE). $N=202$.

This resulted in a difference between disperser and resident thermal phenotype with climates (interaction dispersal status $\mathrm{x}$ preferred temperature: $\chi^{2}=6.56, \mathrm{p}=0.01$, Fig. 2). Natal preferred temperature was on average $5.6^{\circ} \mathrm{C}$ lower for dispersers from 'warm climate' than from 'present climate' while there were no differences between residents from both climates (Fig. 2, dispersers: $\chi^{2}=4.56, p=0.03$, residents: $\chi^{2}=0.30, p=0.59$ ). Dispersal propensity was also lower for juveniles born late in the season (birth-date: estimate \pm SE: $-0.05 \pm 0.02, \chi^{2}$ $=4.25, \mathrm{p}=0.039$ ). 


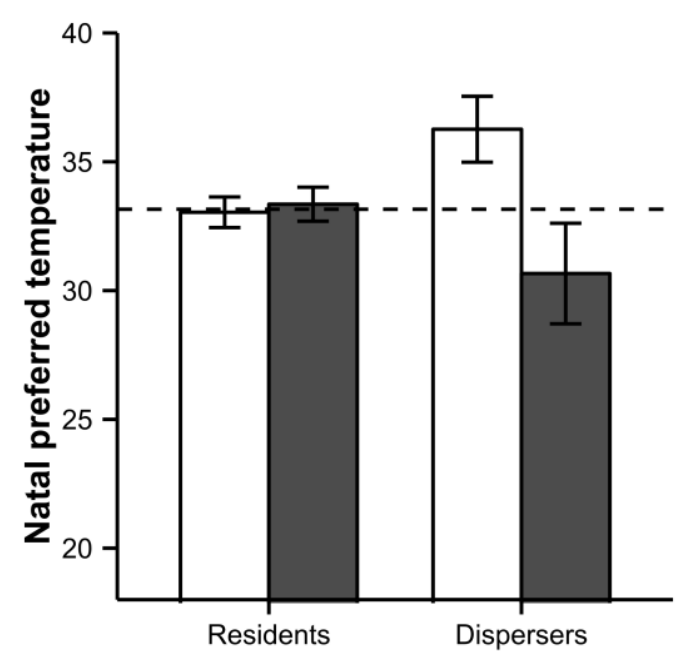

Dispersal status

Figure 2: Natal preferred temperature for dispersing and resident individuals, mean $\pm S E$.

White bars: individuals from present climate treatment. Grey bars: individuals from warm climate treatment. Dashed line: mean juvenile preferred temperature. $N=202$.

We further found that dispersers from 'warm climates' survived better when released into 'present climate' enclosures than when released into 'warm climate' (estimate $\pm \mathrm{SE}=-1.97 \pm$ 0.97, $\mathrm{z}=2.35, \mathrm{p}=0.04$, Fig. 3). There were no survival differences for dispersers from 'present climate' treatments (estimate $\pm \mathrm{SE}=-0.13 \pm 1.51, \mathrm{z}=1.96, \mathrm{p}=0.93$, Fig. 3). Dispersers survived better throughout the summer than residents irrespective of the climatic treatment (estimate $\pm \mathrm{SE}=0.91 \pm 0.40, \mathrm{z}=2.29, \mathrm{p}=0.02$ ), and there were no difference of survival between residents from the two climatic treatments (estimate $\pm \mathrm{SE}=-0.32 \pm 0.23, \mathrm{z}=$ $-1.38, \mathrm{p}=0.17)$ 


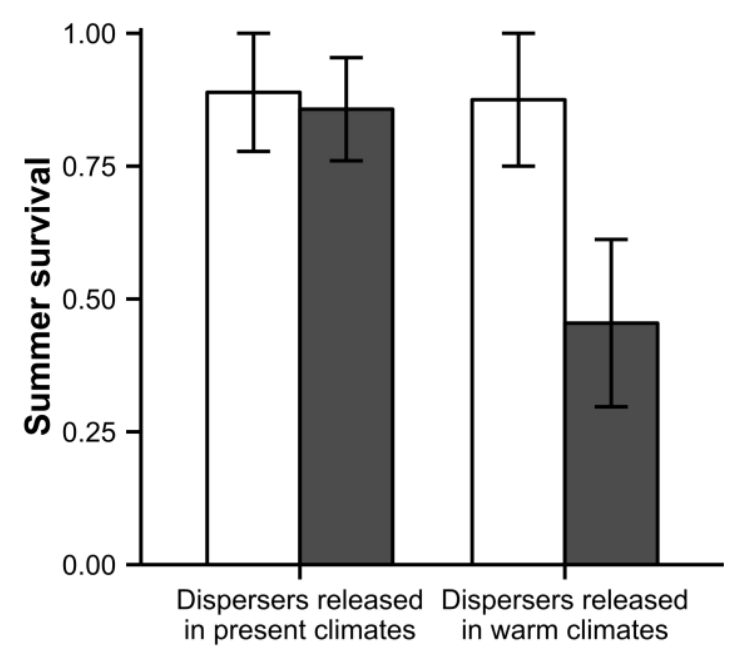

Figure 3: Summer survival for dispersing individuals depending on the climatic conditions of departure and of the climatic conditions of arrival, mean \pm SE. Grey bars: individuals from warm climate treatment. White bars: individuals from present climate treatment. $N=46$.

\section{Discussion}

In this study, we quantified the effects of intraspecific variation in individual preferred temperatures on climate-dependent dispersal behavior in a large experimental set-up. Dispersal did not depend directly on climatic conditions, as we found no global increase or decrease of dispersal propensity in warmer climates. However, climatic conditions both increased and decreased individual dispersal propensity depending on natal preferred temperature, a proxy of thermal optimum (Huey et al. 2012). Such intraspecific variation in thermal physiology and dispersal behavior could have a strong impact on species response to warming climates.

Thermal niche is crucial to species responses to climate change (Deutsch et al. 2008; Sinervo et al. 2010; Huey et al. 2012). However, studies build their understanding of species vulnerability to climate change on mean species responses and rarely consider within-species variation in this response (but see Cobben et al. 2012; Valladares et al. 2014). Thermal 
niches, optimum and preferences strongly vary within ectotherm species (Carretero et al. 2005; Artacho et al. 2013). This variation can result from early developmental plasticity or genetic determinism (broad sense heritability $=0.37$ in this study, but see Paranjpe et al. 2013; Bestion et al. 2014) explaining observed repeatabilities in these traits (Artacho et al. 2013, this study). These variations may induce between-individual variation in dispersal responses to climate warming (Moran et al. 2015). Recent studies aimed at understanding how climate change can affect dispersal behavior (Bonte et al. 2008; Massot et al. 2008; Travis et al. 2013). However, discrepancies in empirical results hamper predictions of future range shift. Indeed, empirical studies showed that warmer conditions can both increase or decrease dispersal rates depending on the species and local conditions (reviewed in Travis et al. 2013). For example, a monitoring of common lizards populations found both a decrease and an increase of dispersal with higher prenatal and postnatal temperatures respectively (Massot et al. 2008). The diversity of dispersal responses can be partly explained by betweenindividual variations in phenotypic traits such as thermal optimum (Clobert et al. 2009). Dispersal decisions result from complex associations between local conditions and phenotype, named condition- and phenotype-dependent dispersal (Clobert et al. 2009). Dispersers often display phenotypic differences in comparison to residents (Bowler \& Benton 2005; Clobert et al. 2009) because certain phenotypes are less adapted to local conditions or better prepared to disperse, and these sets of differences, named dispersal syndromes, vary with ecological conditions of dispersal (Cote \& Clobert 2007; Bonte et al. 2008; Cote et al. 2013; Bestion et al. 2014). Such intraspecific phenotypic variation and its consequences on dispersal require scaling studies down from the species to the population and individual levels. In particular, our present findings show the importance of considering the whole individual internal and external context to better understand the consequences of climate change on dispersal. 
In our study, dispersal inclination was positively related to natal preferred temperature in 'present climates' while this relationship was negative in 'warm climates'. It follows that dispersers from warmer climates had lower natal preferred temperatures than dispersers from 'present climates'. We further found that juvenile dispersing from 'warm climates' survived better when they arrived in 'present climates' than in 'warm climates' but the reverse was not true. Overall, these results suggest that dispersal could be at least partly adaptive, and are coherent with habitat matching hypothesis (Edelaar et al. 2008; Bonte et al. 2014) which predicts that dispersers move between habitats to find environmental conditions which match their phenotypic characteristics and increase their fitness. Along with a lack of climate effects on residents survival, our results suggest that some dispersers may choose habitat increasing their fitness. However, these results should be taken with caution as they rely on a low sample size $(n=46)$ and our experimental design does not fully test for dispersal adaptiveness. First, as dispersers were caught in pitfall traps, their survival probability was measured between this time point and September while residents were not caught in pitfall traps and their survival was quantified on a longer period, between their release and September. Consequently, survival probabilities can only be accurately compared between dispersers' types and not between dispersers and residents. Second, it requires a dedicated design measuring lifetime fitness after preventing dispersal attempts (i.e. releasing dispersers back into their natal habitat) and forcing residents to disperse. However, our present results show that a variation in thermal phenotype can produce opposite dispersal responses hidden behind the lack of global change of dispersal rate at the population level. In natural populations, both a decrease and an increase of dispersal with higher prenatal and postnatal temperatures respectively have been observed (Massot et al. 2008). Our results do not necessarily contradict these observations, as prenatal temperatures can modify maternal conditions and consequently natal preferred temperatures (Paranjpe et al. 2013; Bestion et al. 2014). Prenatal temperature can 
therefore produce juveniles with biased thermal preferences creating the relationship between postnatal temperatures and dispersal behaviors. In natural populations, climate warming was further shown to modify population composition towards phenotypes more adapted to warmer climates (Lepetz et al. 2009), suggesting that climate-induced immigration was different in warm and cold adapted phenotypes.

In a range shift perspective, dispersal syndromes can impact the composition of phenotypes and local adaptation at range edges, and therefore the success and speed of range shift, expansion and retraction. For example, in western bluebirds, a coupling between aggressiveness and dispersal facilitated range expansion (Duckworth \& Badyaev 2007) because higher aggressiveness allowed to better deal with conditions encountered in invaded areas. Disperser phenotypic specificities are often stable over time, either genetically or environmentally inherited, and linked to various other life-history traits, which have thus strong consequences on invasion dynamics (Duckworth \& Badyaev 2007; Cote et al. 2010; Jacob et al. 2015). In a climate warming context, individuals with thermal requirements illadapted to local conditions could disperse to match their habitat choice (Edelaar et al. 2008), and this should promote rapid local adaptation to climatic conditions at both warm and cold margins. At the warm margin (i.e. southern or lower altitude populations), individuals with a phenotype adapted to colder conditions will perceive climate change as a deterioration of thermal habitat more than individuals adapted to warmer conditions. The phenotypedependent dispersal should thus lead to a northwards shift of 'cold adapted' phenotypes towards the center of the range, while 'warm adapted' phenotypes could stay, limiting retraction at the southern margin. At the cold margin, temperature will also increase and individuals with a phenotype adapted to the coldest conditions (lowest preferred temperature) will experience this increase as a habitat deterioration (i.e. external temperatures will go beyond their thermal optimum) and disperse northwards to new habitats beyond northern 
margin that became climatically suitable for 'cold adapted' individuals. It will result into an expanding front made of the 'coldest phenotype'. If preferred temperatures vary locally (i.e. within populations) on the entire species range, we expect this scenario to operate on the entire species range, not only the cold and warm margins.

However, in our study, we used lizards from populations located at the southern margin of the species range and we cannot ensure that dispersal behavior also varies with individual preferred temperatures in colder populations. However, as individual thermal optima also largely vary in northern/high altitude populations (Gvoždík 2002; Carretero et al. 2005), temperature increases should lead to the dispersal of locally 'colder phenotypes' northwards on the entire species range. At a regional scale, a variation in disperser preferred temperature can thus impact the species range dynamics, both at the expanding and retracting margins. A recent modeling study showed for example that the level of between-population variation in thermal optimum and niche breadth had an important impact on predicted species range in a changing climate (Valladares et al. 2014). In unrestricted dispersal scenarios, there was no difference in range distribution between scenarios with and without intraspecific variation. However, when dispersal was limited, species underwent marked range reductions at the retracting margin, with stronger reductions in scenarios accounting for intraspecific variation in thermal niche (Valladares et al. 2014). Within-population variation has, on the contrary, completely opposite effects. Range shift and invasion models predicted that within-population variation in life-history traits decreases extinction risk (Dytham et al. 2014) and that spatial sorting of individuals depending on their traits leads to accelerated range expansions and shifts (Clobert et al. 2009; Fogarty et al. 2011; Dytham et al. 2014). Our results support these models as the non-random (aka directional) dispersal of thermal phenotypes should lead to a northwards move of 'cold adapted' phenotypes with warmer climates in the entire species range and increase local adaptation in comparison to a random dispersal (Jacob et al. 2015). 
Overall, non-random dispersal could contribute to range dynamics both at the southern retracting margin and at the northern expanding front and hence overall to the whole species range shifting.

Our experimental set-up allowed us to study fine-tuned responses to a rapid climate change of $2-3^{\circ} \mathrm{C}$ matching predictions for 2080 (IPCC 2013) independently of potential confounding factors. In a more gradual shift in climatic conditions, non-random dispersal could still influence range shift in a more continuous way. Preferred temperatures vary continuously from cold to warm preferences and thermal conditions also vary gradually in the landscape. At each warming 'step', some individuals will perceive external temperature getting away from their thermal optimum and may disperse to find better suited thermal habitats. Our study demonstrates the importance of integrating a neglected level of biodiversity, intraspecific variation in thermal physiology, to better understand species response to changing world. Indeed, a lack of effect on dispersal at a population level can hide an effect on dispersers phenotype which can strongly alter population functioning. Given the importance of intraspecific variation in ecological and evolutionary processes (Hughes et al. 2008; Bolnick et al. 2011; Dall et al. 2012), we advocate acknowledging individual variation in preferred temperature and dispersal as one of the priorities in climate change research and range shift modeling.

\section{Acknowledgements}

We thank Aimeric Teyssier, all the interns who participated to the fieldwork (Antoine Cave, Bastien Remurier, Laure Geidel and Alice Fournier), three anonymous referees and the editor. This work has been done in the Station d'Ecologie Expérimentale de Moulis (CNRS, USR 2936) and the Laboratoire Evolution et Diversité Biologique (CNRS, UPS, UMR 5174), part of the Laboratoire d'Excellence (LABEX) entitled TULIP (ANR -10-LABX-41). JCo 
was supported by an ANR-12-JSV7-0004-01. JCl was supported by the ANR programs

Mobigen and Indhet, and the ANR Infrastructure grant AnaEE-France.

\section{Authors contributions}

EB and JCo created the experimental design, performed the experiment and analyzed the data;

EB wrote the first draft and all authors contributed substantially to revisions.

\section{References}

1.

Agasyan, A., Avci, A, Tuniyev, B, Crnobrnja Isailovic, J, Lymberakis, P, Andrén, et al. (2010). Zootoca vivipara. IUCN 2013 IUCN Red List Threat. SpeciesVersion 20132.

\section{2.}

Araújo, M.B., Ferri-Yáñez, F., Bozinovic, F., Marquet, P.A., Valladares, F. \& Chown, S.L. (2013). Heat freezes niche evolution. Ecol. Lett., 16, 1206-1219.

3.

Artacho, P., Jouanneau, I. \& Le Galliard, J.-F. (2013). Interindividual Variation in Thermal Sensitivity of Maximal Sprint Speed, Thermal Behavior, and Resting Metabolic Rate in a Lizard. Physiol. Biochem. Zool., 86, 458-469.

4.

Bestion, E., Cucherousset, J., Teyssier, A. \& Cote, J. (2015). Non-consumptive effects of a top-predator decrease the strength of the trophic cascade in a four-level terrestrial food web. Oikos.

5.

Bestion, E., Teyssier, A., Aubret, F., Clobert, J. \& Cote, J. (2014). Maternal exposure to predator scents: offspring phenotypic adjustment and dispersal. Proc. R. Soc. B Biol. Sci., 281, 20140701.

6.

Bolnick, D.I., Amarasekare, P., Araújo, M.S., Bürger, R., Levine, J.M., Novak, M., et al. (2011). Why intraspecific trait variation matters in community ecology. Trends Ecol. Evol., 26, 183-192.

7.

Bonte, D., De Roissart, A., Wybouw, N. \& Van Leeuwen, T. (2014). Fitness maximization by dispersal: evidence from an invasion experiment. Ecology, 95, 3104-3111.

8.

Bonte, D., Travis, J.M.J., Clercq, N.D., Zwertvaegher, I. \& Lens, L. (2008). Thermal conditions during juvenile development affect adult dispersal in a spider. Proc. Natl. Acad. Sci., 105, 17000-17005. 
9.

Boudjemadi, K., Lecomte, J. \& Clobert, J. (1999). Influence of connectivity on demography and dispersal in two contrasting habitats: an experimental approach. J. Anim. Ecol., 68, 12071224.

10.

Bowler, D.E. \& Benton, T.G. (2005). Causes and consequences of animal dispersal strategies: relating individual behaviour to spatial dynamics. Biol. Rev., 80, 205-225.

11.

Carretero, M.A., Roig, J.M. \& Llorente, G.A. (2005). Variation in preferred body temperature in an oviparous population of Lacerta (Zootoca) vivipara . Herpetol. J., 15, 51-55.

12.

Clobert, J., Le Galliard, J.F., Cote, J., Meylan, S. \& Massot, M. (2009). Informed dispersal, heterogeneity in animal dispersal syndromes and the dynamics of spatially structured populations. Ecol. Lett., 12, 197-209.

13.

Clobert, J., Massot, M., Lecomte, J., Sorci, G., De Fraipont, M. \& Barbault, R. (1994). Determinants of dispersal behavior: the common lizard as a case study. In: Lizard Ecology: Historical and Experimental Perspectives (eds. Vitt, L.J. \& Pianka, E.R.). Princeton University Press.

14.

Cobben, M.M.P., Verboom, J., Opdam, P.F.M., Hoekstra, R.F., Jochem, R. \& Smulders, M.J.M. (2012). Wrong place, wrong time: climate change-induced range shift across fragmented habitat causes maladaptation and declined population size in a modelled bird species. Glob. Change Biol., 18, 2419-2428.

15.

Comte, L., Murienne, J. \& Grenouillet, G. (2014). Species traits and phylogenetic conservatism of climate-induced range shifts in stream fishes. Nat. Commun., 5.

16.

Cote, J. \& Clobert, J. (2007). Social personalities influence natal dispersal in a lizard. Proc. $R$. Soc. B Biol. Sci., 274, 383-390.

17.

Cote, J., Clobert, J., Brodin, T., Fogarty, S. \& Sih, A. (2010). Personality-dependent dispersal: characterization, ontogeny and consequences for spatially structured populations. Philos.

Trans. R. Soc. B Biol. Sci., 365, 4065-4076.

18.

Cote, J., Fogarty, S., Tymen, B., Sih, A. \& Brodin, T. (2013). Personality-dependent dispersal cancelled under predation risk. Proc. R. Soc. B Biol. Sci., 280, 20132349.

19. 
Dall, S.R.X., Bell, A.M., Bolnick, D.I. \& Ratnieks, F.L.W. (2012). An evolutionary ecology of individual differences. Ecol. Lett., 15, 1189-1198.

20.

Van Damme, R., Bauwens, D. \& Verheyen, R.F. (1990). Evolutionary Rigidity of Thermal Physiology: The Case of the Cool Temperate Lizard Lacerta vivipara . Oikos, 57, 61.

21.

Deutsch, C.A., Tewksbury, J.J., Huey, R.B., Sheldon, K.S., Ghalambor, C.K., Haak, D.C., et al. (2008). Impacts of climate warming on terrestrial ectotherms across latitude. Proc. Natl. Acad. Sci., 105, 6668-6672.

22.

Duckworth, R.A. \& Badyaev, A.V. (2007). Coupling of dispersal and aggression facilitates the rapid range expansion of a passerine bird. Proc. Natl. Acad. Sci., 104, 15017.

23.

Dytham, C., Travis, J.M.J., Mustin, K. \& Benton, T.G. (2014). Changes in species' distributions during and after environmental change: which eco-evolutionary processes matter more? Ecography, 37, 1210-1217.

24.

Edelaar, P., Siepielski, A.M. \& Clobert, J. (2008). Matching Habitat Choice Causes Directed Gene Flow: A Neglected Dimension in Evolution and Ecology. Evolution, 62, 2462-2472.

25.

Falconer, D.S. \& Mackay, T.F.C. (1996). Introduction to quantitative genetics, 4th edition.

26.

Fogarty, S., Cote, J. \& Sih, A. (2011). Social Personality Polymorphism and the Spread of Invasive Species: A Model. Am. Nat., 177, 273-287.

27.

Gvoždík, L. (2002). To heat or to save time? Thermoregulation in the lizard Zootoca vivipara (Squamata: Lacertidae) in different thermal environments along an altitudinal gradient. Can. J. Zool., 80, 479-492.

28.

Gvoždík, L. \& Castilla, A.M. (2001). A Comparative Study of Preferred Body Temperatures and Critical Thermal Tolerance Limits among Populations of Zootoca vivipara (Squamata: Lacertidae) along an Altitudinal Gradient. J. Herpetol., 35, 486.

29.

Huey, R.B., Kearney, M.R., Krockenberger, A., Holtum, J.A.M., Jess, M. \& Williams, S.E. (2012). Predicting organismal vulnerability to climate warming: roles of behaviour, physiology and adaptation. Philos. Trans. R. Soc. B Biol. Sci., 367, 1665-1679.

30 .

Hughes, A.R., Inouye, B.D., Johnson, M.T.J., Underwood, N. \& Vellend, M. (2008).

Ecological consequences of genetic diversity. Ecol. Lett., 11, 609-623. 
31.

IPCC. (2013). Climate change 2013: the physical science basis : Working Group I contribution to the fifth assessment report of the Intergovernmental Panel on Climate Change. Cambridge University Press, Cambridge, United Kingdom and New York, NY, USA.

32.

Jacob, S., Bestion, E., Legrand, D., Clobert, J. \& Cote, J. (2015). Habitat matching and spatial heterogeneity of phenotypes: implications for metapopulation and metacommunity functioning. Evol. Ecol.

33.

Klok, C.J. \& Chown, S.L. (2003). Resistance to temperature extremes in sub-Antarctic weevils: interspecific variation, population differentiation and acclimation. Biol. J. Linn. Soc., 78, 401-414.

34.

Legrand, D., Guillaume, O., Baguette, M., Cote, J., Trochet, A., Calvez, O., et al. (2012). The Metatron: an experimental system to study dispersal and metaecosystems for terrestrial organisms. Nat. Methods, 9, 828-833.

35.

Lepetz, V., Massot, M., Chaine, A.S. \& Clobert, J. (2009). Climate warming and the evolution of morphotypes in a reptile. Glob. Change Biol., 15, 454-466.

36.

Massot, M., Clobert, J. \& Ferrière, R. (2008). Climate warming, dispersal inhibition and extinction risk. Glob. Change Biol., 14, 461-469.

37.

Massot, M., Clobert, J., Pilorge, T., Lecomte, J. \& Barbault, R. (1992). Density Dependence in the Common Lizard: Demographic Consequences of a Density Manipulation. Ecology, 73, $1742-1756$.

38.

Moran, E.V., Hartig, F. \& Bell, D.M. (2015). Intraspecific trait variation across scales: implications for understanding global change responses. Glob. Change Biol., n/a-n/a.

39.

Nakagawa, S. \& Schielzeth, H. (2010). Repeatability for Gaussian and non-Gaussian data: a practical guide for biologists. Biol. Rev., 85, 935-956.

40.

Paranjpe, D.A., Bastiaans, E., Patten, A., Cooper, R.D. \& Sinervo, B. (2013). Evidence of maternal effects on temperature preference in side-blotched lizards: implications for evolutionary response to climate change. Ecol. Evol., 3, 1977-1991.

41. 
Parmesan, C. (2006). Ecological and Evolutionary Responses to Recent Climate Change. Annu. Rev. Ecol. Evol. Syst., 37, 637-669.

42.

Patterson, J.W. \& Davies, P.M.C. (1978). Preferred body temperature: Seasonal and sexual differences in the lizard Lacerta vivipara. J. Therm. Biol., 3, 39-41.

43.

Pauls, S.U., Nowak, C., Bálint, M. \& Pfenninger, M. (2013). The impact of global climate change on genetic diversity within populations and species. Mol. Ecol., 22, 925-946.

44.

Sih, A., Cote, J., Evans, M., Fogarty, S. \& Pruitt, J. (2012). Ecological implications of behavioural syndromes. Ecol. Lett., 15, 278-289.

45.

Sinervo, B., Méndez-de-la-Cruz, F., Miles, D.B., Heulin, B., Bastiaans, E., Villagrán-Santa Cruz, M., et al. (2010). Erosion of lizard diversity by climate change and altered thermal niches. Science, 328, 1354-1354.

46.

Thomas, C.D. (2010). Climate, climate change and range boundaries. Divers. Distrib., 16, 488-495.

47.

Thomas, C.D., Franco, A.M.A. \& Hill, J.K. (2006). Range retractions and extinction in the face of climate warming. Trends Ecol. Evol., 21, 415-416.

48.

Travis, J.M.J., Delgado, M., Bocedi, G., Baguette, M., Bartoń, K., Bonte, D., et al. (2013). Dispersal and species' responses to climate change. Oikos, 122, 1532-1540.

49.

Valladares, F., Matesanz, S., Guilhaumon, F., Araújo, M.B., Balaguer, L., Benito-Garzón, M., et al. (2014). The effects of phenotypic plasticity and local adaptation on forecasts of species range shifts under climate change. Ecol. Lett., 17, 1351-1364.

50 .

Zuur, A.F., Ieno, E.N., Walker, N.J., Saveliev, A.A. \& Smith, G.M. (2009). Mixed Effects Models and Extensions in Ecology with R. Springer. New York. 


\section{Appendix}

Table A1: Comparative statistics of preferred temperatures in adult Zootoca vivipara from different European populations. Homologous comparisons are performed between Cevennes populations (our study) and other localities (samples from the literature) by means of t-tests, using the same methodology as Carretero et al., 2005. * Significant after sequential Bonferonni correction.

\begin{tabular}{|c|c|c|c|c|c|c|c|c|}
\hline \multirow[t]{2}{*}{ Area } & \multirow[t]{2}{*}{ Reference } & \multicolumn{2}{|c|}{$\begin{array}{l}\text { Preferred } \\
\text { temperature }\end{array}$} & \multirow[t]{2}{*}{$\mathrm{n}$} & \multicolumn{4}{|c|}{$\begin{array}{c}\text { Compared to our Cevennes } \\
\text { populations }\end{array}$} \\
\hline & & mean & sd & & $\mathrm{t}$-value & df & p-value & \\
\hline Great Britain & Carretero et al., 2005 & 31 & 0.9 & 12 & -3.74 & 11 & 0.003 & $*$ \\
\hline Austria & Carretero et al., 2005 & 32.1 & 2.9 & 92 & -0.97 & 91 & 0.34 & \\
\hline Belgium & Carretero et al., 2005 & 32.3 & 2.5 & 151 & -0.59 & 150 & 0.56 & \\
\hline Czech Republic & Carretero et al., 2005 & 31.4 & 1.3 & 24 & -2.73 & 23 & 0.01 & \\
\hline Pyrenees & Carretero et al., 2005 & 32.3 & 1.8 & 24 & -0.46 & 23 & 0.66 & \\
\hline Belgium & Carretero et al., 2005 & 32.3 & 2 & 100 & -0.59 & 99 & 0.56 & \\
\hline Belgium & Carretero et al., 2005 & 33.3 & 1.1 & 128 & 2.38 & 127 & 0.02 & \\
\hline Czech Republic & Carretero et al., 2005 & 31.5 & 1.4 & 12 & -2.00 & 11 & 0.07 & \\
\hline Pyrenees & Carretero et al., 2005 & 33.4 & 1.5 & 6 & 1.28 & 6 & 0.25 & \\
\hline Belgium & Carretero et al., 2005 & 34 & 1.3 & 19 & 3.43 & 18 & 0.003 & $*$ \\
\hline Belgium & Carretero et al., 2005 & 32.7 & 2.3 & 60 & 0.42 & 59 & 0.68 & \\
\hline Czech Republic & Carretero et al., 2005 & 31.3 & 1.4 & 12 & -2.39 & 11 & 0.04 & \\
\hline Pyrenees & Carretero et al., 2005 & 31.9 & 1.7 & 18 & -1.22 & 17 & 0.24 & \\
\hline Belgium & Carretero et al., 2005 & 30.3 & 2.6 & 74 & -5.11 & 73 & $<0.0001$ & $*$ \\
\hline Belgium & Carretero et al., 2005 & 30 & 1.3 & 10 & -4.88 & 9 & 0.0009 & $*$ \\
\hline Czech Republic & Carretero et al., 2005 & 29.5 & 0.5 & 7 & -8.27 & 6 & $<0.0001$ & $*$ \\
\hline Pyrenees & Carretero et al., 2005 & 28.5 & 1.5 & 12 & -7.53 & 11 & $<0.0001$ & $*$ \\
\hline Cevennes & Artacho et al., 2013 & 33.14 & 1.14 & 200 & 1.92 & 199 & 0.06 & \\
\hline
\end{tabular}


Table A2: Comparison of the best models investigating juvenile dispersal propensity through their AIC.

\begin{tabular}{|c|c|c|c|}
\hline Model & df & AIC & $\triangle \mathrm{AIC}$ \\
\hline Temperature treatment $*$ Preferred temperature at birth + Birthdate $+(1 \mid$ Enclosure $)$ & 6 & 169.09 & \\
\hline Temperature treatment $*$ Preferred temperature at birth $+(1 \mid$ Enclosure $)$ & 5 & 171.96 & 2.87 \\
\hline Birthdate $+(1 \mid$ Enclosure $)$ & 3 & 172.35 & 3.26 \\
\hline Preferred temperature at birth + Birthdate $+(1 \mid$ Enclosure $)$ & 4 & 172.94 & 3.85 \\
\hline Temperature treatment + Birthdate $+(1 \mid$ Enclosure $)$ & 4 & 174.13 & 5.04 \\
\hline (1|Enclosure) & 2 & 174.30 & 5.21 \\
\hline Temperature treatment + Preferred temperature at birth + Birthdate $+(1 \mid$ Enclosure $)$ & 5 & 174.69 & 5.60 \\
\hline Preferred temperature at birth $+(1 \mid$ Enclosure $)$ & 3 & 175.19 & 6.10 \\
\hline Temperature treatment $+(1 \mid$ Enclosure $)$ & 3 & 176.14 & 7.05 \\
\hline Temperature treatment + Preferred temperature at birth $+(1 \mid$ Enclosure $)$ & 4 & 177.00 & 7.91 \\
\hline
\end{tabular}

